\title{
Photovoltaic Energy Conversion Systems with Sliding Mode Control
}

\author{
Mehmetcan Gursoy ${ }^{1,+}$, Guangping Zhuo ${ }^{2,+}$, Andy G. Lozowski ${ }^{3,+}$ and Xin Wang ${ }^{3, *,+(D)}$ \\ 1 Department of Electrical and Computer Engineering, Kansas State University, Manhattan, KS 66506, USA; \\ gursoy@ksu.edu \\ 2 Department of Computer Science, Taiyuan Normal University, Taiyuan 030619, China; \\ zhuoguangping@163.com \\ 3 Department of Electrical and Computer Engineering, Southern Illinois University, \\ Edwardsville, IL 62026, USA; alozows@siue.edu \\ * Correspondence: xwang@siue.edu \\ + These authors contributed equally to this work.
}

Citation: Gursoy, M.; Zhuo, G.; Lozowski, A.G.; Wang, X. Photovoltaic Energy Conversion Systems with Sliding Mode Control. Energies 2021, 14, 6071. https:// doi.org/10.3390/en14196071

Academic Editor: Anastasios Dounis

Received: 8 August 2021

Accepted: 16 September 2021

Published: 24 September 2021

Publisher's Note: MDPI stays neutral with regard to jurisdictional claims in published maps and institutional affiliations.

Copyright: (c) 2021 by the authors. Licensee MDPI, Basel, Switzerland. This article is an open access article distributed under the terms and conditions of the Creative Commons Attribution (CC BY) license (https:// creativecommons.org/licenses/by/ $4.0 /)$.

\begin{abstract}
A new sliding-mode-control-based power conversion scheme is proposed for photovoltaic energy conversion systems. The perturbation and observation $(\mathrm{P} \& \mathrm{O})$ maximum power-point tracking (MPPT) approach is adopted for optimizing the power generation capabilities from solar panels. Due to the inherent nonlinear dynamics of power converters, we need to adopt a nonlinear control approach to optimize the energy conversion efficiency and tolerate the fluctuations and changes of load and sunlight irradiance. In this manuscript, novel first-and higher-order sliding mode control approaches are proposed, aiming to provide a systematic approach for the robust and optimal control of solar energy conversion, which guarantees Lyapunov stability and consistent performance in the face of external perturbations and disturbances. Moreover, to eliminate the chattering phenomenon inherent in the first-order approach, super-twisting second-order sliding mode control is developed for the buck-boost converter. Furthermore, the output of DC-DC converter supplies a voltage-oriented-control (VOC)-based space-vector pulse-width-modulated inverter to generate three-phase AC power to the grid. To demonstrate the robustness and effectiveness of the proposed scheme, computer simulations and dSPACE hardware-in-the-loop platform have been carried on for examining the proposed sliding-mode-control-based solar energy conversion system.
\end{abstract}

Keywords: sliding mode control; DC-DC converter; solar energy systems

\section{Introduction}

Solar power generation, particularly photovoltaic (PV) power, is one of the most promising renewable energy resources of the 21st century. Due to the semiconductor material properties of solar cells, photovoltaic panels have inconsistent output characteristics under changing weather, load variations, and varying sunlight irradiation conditions. Dynamically matching solar panels' internal resistance with the power system's equivalent Thevenin resistance is the key to maximizing power generation and reducing power losses [1]. Therefore, maximum power-point tracking is crucial for optimizing energy conversion efficiency. Note that one of the major control challenges of a PV system is the time-varying DC-link voltage at the output of DC-DC converters. Flexible, distributed power generation with high penetration in $\mathrm{PV}$ panels requires a robust DC-DC converter control scheme to minimize output voltage variations and achieve a stable DC voltage level.

Despite the nonlinear nature of DC-DC converter characteristics [2], classical PID control based on the Jacobian linearization of the nonlinear dynamics is the most commonly used control approach in practical high-power converter applications, which typically offers unsatisfactory performance along with inadequate power conversion efficiencies. Hence, a robust and optimal nonlinear control technique is desirable to achieve a better 
performance under high-level system nonlinearity, time-varying sunlight irradiation and load fluctuations conditions [3-5]. Among various nonlinear control methods, the slidingmode control method has been one of the most widely used nonlinear control techniques for powering electronic devices [6]. However, it is well-known that the chattering phenomenon is the major drawback of the first-order sliding mode method. Non-ideal power switching and high-frequency oscillation causes a pronounced chattering phenomenon, which limits the application of the first-order sliding mode approach $[7,8]$. To eliminate the chattering phenomenon, this manuscript also presents a novel super-twisting-based second-order sliding mode control with much-reduced chattering phenomenon and superior control accuracy for the DC-DC converters [4].

In this paper, a commercially available $270 \mathrm{~W}$ "SolarWorld Sunmodule-Plus SW 270 Mono Black" photovoltaic panel is controlled to achieve the maximum power-point tracking (MPPT), through the perturbation and observation (P\&O) MPPT algorithm. The novel first- and higher-order sliding mode control systems are developed for the buck-boost converter to optimize power conversion performance. Figure 1 depicts the overall photovoltaic energy conversion system block diagram. The output of the PV module is fed to the boost converter, by which the maximum power point tracking (MPPT) can be achieved. The measured solar panel voltage $V_{\text {panel }}$ and current $I_{\text {panel }}$ are fed to the MPPT controller, and the output of MPPT controller regulates the output of boost converter to meet the voltage requirement for charging the battery pack. At the next stage, the battery feeds the buck-boost converter, the output of which is connected to the common DC link. The capacitor voltage $V_{c}$ and inductor current $i_{L}$ of the buck-boost converter are sent to the sliding mode controller (SMC), and the output of SMC governs the gate signals of the IGBT converter. In the last stage, the output of DC-DC converter is further connected to a voltage-oriented control (VOC) based space-vector pulse-width-modulated high-power inverter, which supplies three-phase power to the micro-grid or isolated three-phase AC loads $[9,10]$.

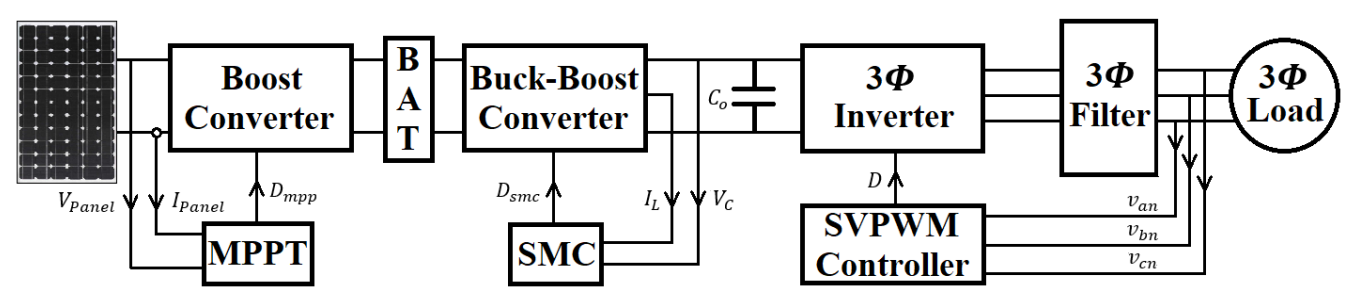

Figure 1. Overall photovoltaic energy conversion system block diagram.

\section{Mathematical Modeling of Photovoltaic Modules}

Photovoltaic modules convert solar irradiance into electrical energy via exciting electrons in semiconductor materials, such as monocrystalline and polycrystalline silicon. Solar panels are often modelled as a single-diode equivalent circuit model, as shown in Figure 2.

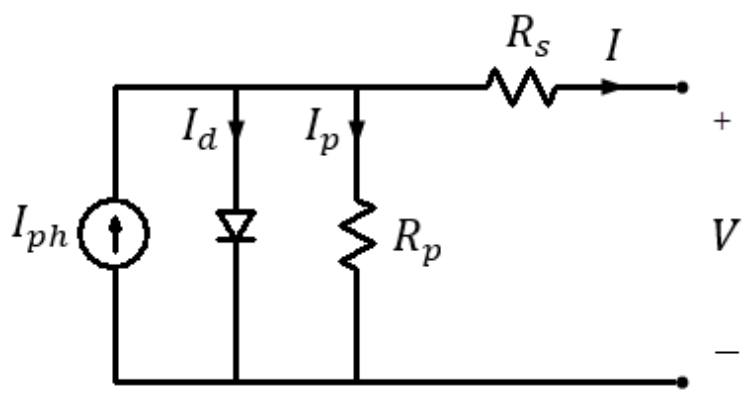

Figure 2. Solar cell single-diode equivalent circuit diagram.

The commercially available "SolarWorld Sunmodule Plus SW 270 Mono Black" is utilized in our studies, the ratings of which are summarized in the module data-sheet 
under the "Standard Test Conditions (STC)" section. The STC is performed under the condition

$$
\begin{gathered}
G=1000 \frac{\mathrm{W}}{\mathrm{m}^{2}} \\
T_{\text {ref }}=25{ }^{\circ} \mathrm{C} \\
\text { A.M }=1.5
\end{gathered}
$$

where $G, T_{\text {ref }}$, and $A . M$ denote irradiance (the power of solar radiation per $\mathrm{m}^{2}$ ), operational cell temperature, and air mass (relative thickness of atmosphere), respectively. The panel's output response under the testing conditions [11] are summarized in Table 1.

Table 1. SolarWorld Sunmodule Plus SW 270 Mono Black Panel ratings.

\begin{tabular}{ccc}
\hline$P_{\text {max }}$ & $270 \mathrm{~W}_{p}$ & Panel rated power at MPP \\
$V_{o c}$ & $39.2 \mathrm{~V}$ & Panel open-circuit V \\
$V_{\text {mpp }}$ & $30.9 \mathrm{~V}$ & Panel rated voltage at MPP \\
$I_{s c}$ & $9.44 \mathrm{~A}$ & Panel short-circuit I \\
$I_{m p p}$ & $8.81 \mathrm{~A}$ & Panel rated current at MPP \\
$\eta_{m}$ & $16.10 \%$ & Panel efficiency \\
$T C P_{m p p}$ & $-0.43 \% /{ }^{\circ} \mathrm{C}$ & Power temp coeff at MPP \\
$T C I_{S c}$ & $0.044 \% /{ }^{\circ} \mathrm{C}$ & SC temperature coefficient at MPP \\
$T C V_{o c}$ & $-0.31 \% /{ }^{\circ} \mathrm{C}$ & OC temperature coefficient at MPP \\
$N_{c e l l}$ & 60 & Number of cells per panel \\
$T Y P$ & Monocrystalline & Cell type \\
\hline
\end{tabular}

Leveraging KCL in Figure 2, the analytical model for panel output current $I$ becomes

$$
I=I_{p h}-I_{d}-I_{p}
$$

where $I_{p h}, I_{d}, I_{p}, I, R_{p}, R_{s}$, and $V$ denote the current produced by photons, diode current, cell's internal parallel resistance current, cell output current, internal shunt resistance, internal series resistance, and output voltage, respectively. Current produced by photon is represented with a constant current source.

It should be noted that photon current $I_{p h}$ depends on solar irradiation and PV cell temperature. The amount of $I_{p h}$ produced by a solar cell is given as

$$
I_{p h}=I_{s c}+T C I_{s c}\left(T_{\text {panel }}-T_{\text {ref }}\right)\left(\frac{G}{G_{\text {nom }}}\right)
$$

Considering semiconductor material properties, diode current $I_{d}$ becomes

$$
I_{d}=I_{s a t}\left[e^{\frac{q\left(V+\left(I R_{s}\right)\right)}{N_{s} k A T_{r e f}}}-1\right]
$$

Saturation current depends on the reverse-saturation effect of the semiconductor, which can be characterized by (4) and (5).

$$
\begin{gathered}
I_{\text {sat }}=I_{\text {rev_sat }}\left(\frac{T_{\text {panel }}}{T_{\text {ref }}}\right)^{3}\left[e^{\frac{q V_{q}}{k A}\left(\frac{1}{T_{\text {ref }}}-\frac{1}{T_{\text {panel }}}\right)}\right] \\
I_{\text {rev_sat }}=\frac{I_{s c}}{\left(e^{\frac{q V_{o c}}{N_{s} k A T_{r e f}}}\right)-1}
\end{gathered}
$$

The internal resistances $R_{p}$ and $R_{s}$ can be estimated by using (6) and (7).

$$
R_{p} \approx \frac{100 V_{o c}}{I_{S C}}
$$




$$
R_{s} \approx \frac{0.01 V_{o c}}{I_{S c}}
$$

Hence, the resultant PV panel output current $I$ is finally reached as

$$
I=I_{p h}-I_{s a t}\left[e^{\frac{q\left(V+\left(I R_{s}\right)\right)}{N_{s} k A T_{r e f}}}-1\right]-\frac{V+I R_{s}}{R_{p}}
$$

where $q, V_{q}, N_{s}, k, A, I_{s a t}, I_{r e v \_s a t}$, and $G_{n o m}$ are electron charge, crystal-silicon bandgap voltage, number of solar cells in series, Boltzmann's constant, diode ideality factor, diode saturation current, diode reverse-saturation current, nominal solar irradiance, respectively, [12,13].

It should be noted that the PV panel power rating changes as the power temperature coefficient changes, under different panel temperatures. Equation (9) below clarifies how the output power varies, as the ambient temperature changes [1].

$$
P_{\text {out }}=P_{m p p}+\left[T_{\text {panel }}-T_{\text {ref }}\right] \times T C P_{m p p}
$$

Based on the aforementioned photovoltaic modules ratings, mathematical modelling, and underlying dynamics analysis, single solar panel simulations are conducted in the MATLAB/Simulink environments. The P-V characteristics of the solar panel are shown in Figures 3 and 4, while I-V results are given in Figures 5 and 6 under time-varying solar irradiation and ambient temperature conditions.

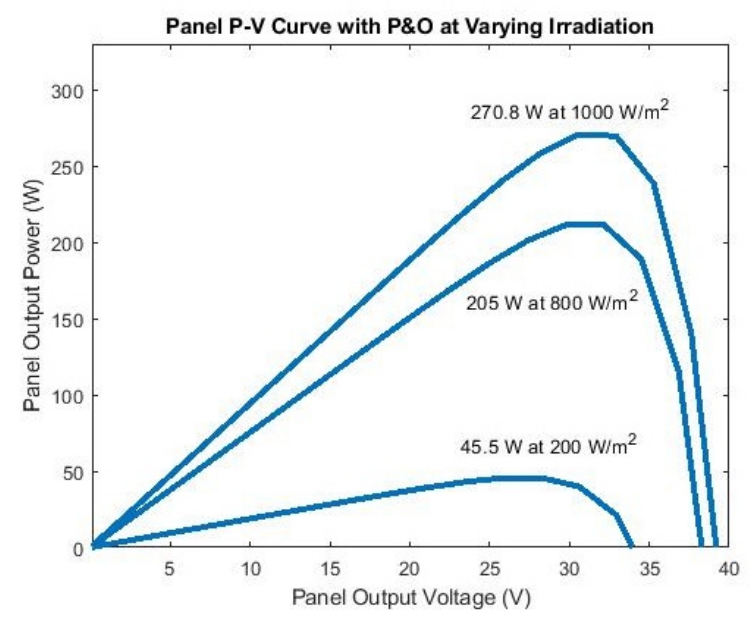

Figure 3. P-V characteristic under changing irradiation.

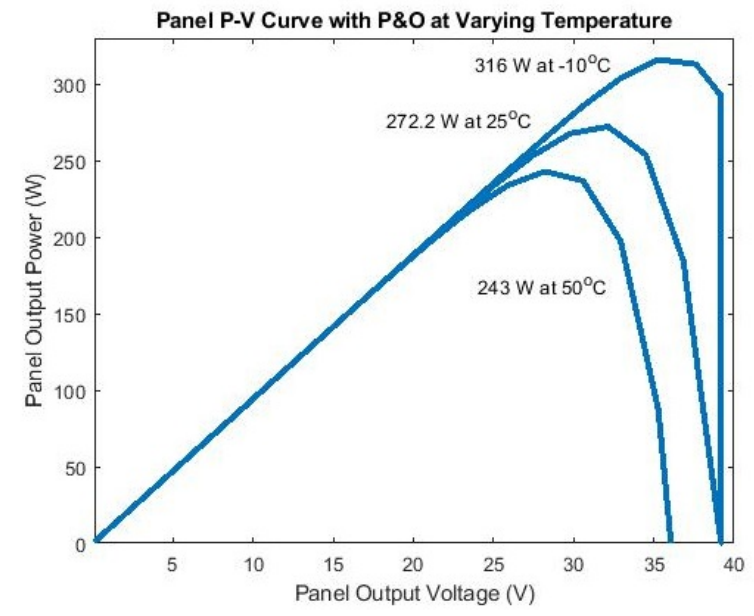

Figure 4. P-V characteristic under changing temperature. 


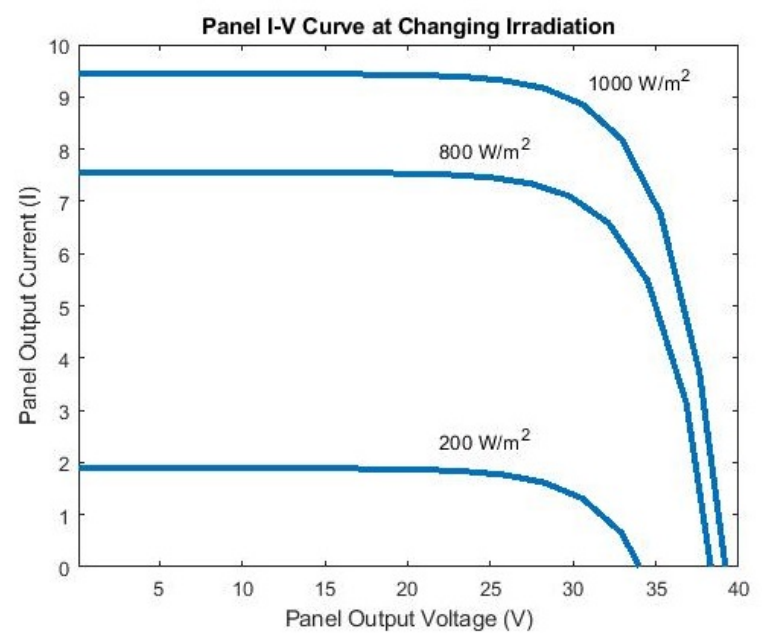

Figure 5. I-V characteristic under changing irradiation.

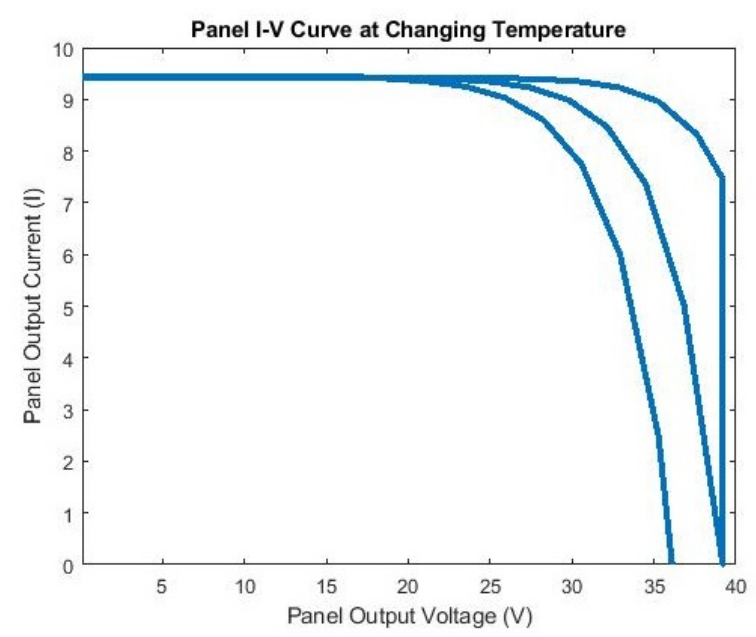

Figure 6. I-V characteristic under changing temperature.

\section{Maximum Power Point Tracking Algorithm}

Figure 3 illustrates that $P_{m p p}$ is reached at the maximum power-point, when the derivative of each curve, representing the solar panel output power at different irradiation ratings, is set to be zero. If maximum power-point tracking control were not utilized, solar panels would never maintain their operation at the peak power generation condition, and the power efficiency would be significantly reduced. Among various MPPT approaches, the perturbation and observation ( $\mathrm{P} \& \mathrm{O}$ ) (hill climbing) method is an effective and robust maximum power-point tracking (MPPT) technique which boosts both accuracy and efficiency. $\mathrm{P} \& \mathrm{O}$ approach has the properties of impedance matching for optimum power transfer. This feature is similar to the incremental conductance method (ICM), hence, the $\mathrm{P} \& \mathrm{O}$ also known as the modified version of ICM [14-25].

The P\&O operation starts by sensing panel current $I_{k}$ and voltage $V_{k}$, then the solar panel power can be computed as $P_{k}=V_{k} I_{k}$ and compared with the previous rating $P_{k-1}$ continuously.

$$
\begin{aligned}
\Delta P & =P_{k}-P_{k-1} \\
\Delta V & =V_{k}-V_{k-1}
\end{aligned}
$$

If the solar panel operating-point is located on the left wing of the maximum powerpoint (MPP), and if power is moving upwards on the graph $\Delta P>0$, the changes in both power and voltage become positive, i.e., $\Delta P \cdot \Delta V>0$. In this case, panel voltage 
is supposed to be increased $\Delta V>0$ by changing the duty cycle to reach the maximum capable power-rating of the panel. On the other hand, if the panel voltage is increased too much, and the maximum power-point is passed, the PV module voltage needs to be decreased by altering the duty-cycle to reach the peak power-point again $\Delta P \cdot \Delta V<0$. Moreover, once the maximum power point $\Delta P \cdot \Delta V=0$ neighborhood is achieved, the dutycycle ripples with a small step size to maintain the operating point, staying within that region. Therefore, the P\&O MPPT controller can be self-adjusted to reach the maximum power-point condition.

\section{Nonlinear Dynamics of Buck-Boost Converter}

A buck-boost converter topology is shown in Figure 7. The circuit consists of a voltage source $(E)$, inductor $(L)$, capacitor $(C)$, load resistance $(R)$, diode $(D)$, and power switching device $(Q)$. A buck-boost converter has positive polarity on the input voltage and negative polarity on the output voltage.

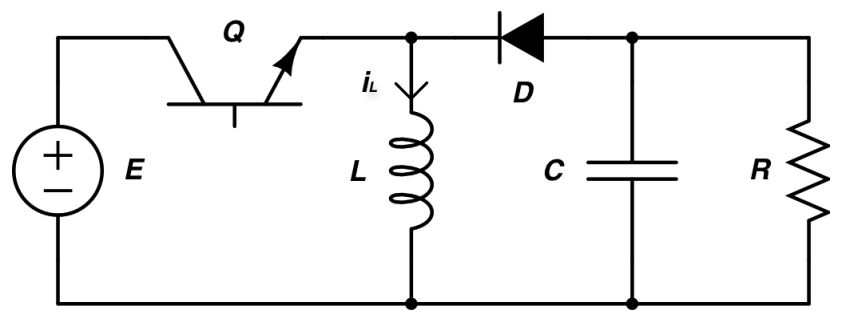

Figure 7. Buck-boost converter diagram.

When the switching device $Q$ is in the conduction mode, current flows through the inductor due to reverse biased diode connection, which energizes the inductor and induces voltage of $E$. The conduction period is assigned as $D T$, where $D$ and $T$ are the duty-cycle ratio and the switching period, respectively. When $Q$ is open-circuited, the inductor dis-energizes, and current flows through the resistor via the diode. The voltage across the inductor becomes $-v_{\text {out }}$. The non-conducting period is defined as $(1-D) T$. The buck-boost converter's equivalent circuit diagrams during the "conducting" and "non-conducting" stages are depicted in Figures 8 and 9.

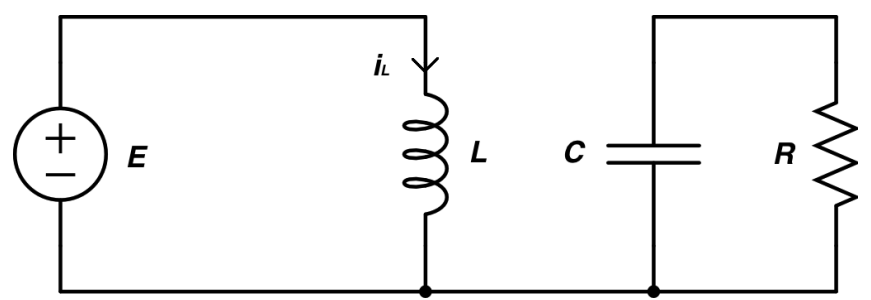

Figure 8. Buck-boost converter-switch "ON".

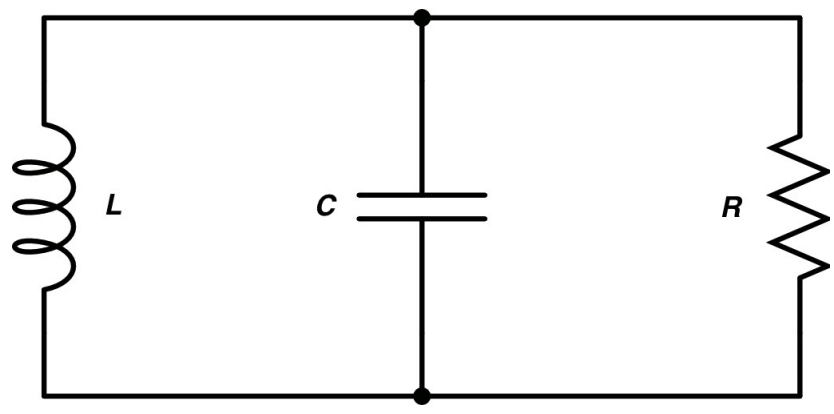

Figure 9. Buck-boost converter—switch "OFF". 
Denote $u$ as the system control input. In another word, the switch $Q$ is on when $u=1$, and is off when $u=0$. When the switching device is closed-circuited, i.e., $u=1$, the state-space model of a buck-boost converter is given as

$$
\begin{gathered}
L \frac{d i_{L}}{d t}=E \\
C \frac{d v_{C}}{d t}=\frac{-v_{C}}{R}
\end{gathered}
$$

Similarly, when the switching device is open-circuited, i.e., $u=0$, we have

$$
\begin{aligned}
L \frac{d i_{L}}{d t} & =v_{C} \\
C \frac{d v_{C}}{d t} & =-i_{L}-\frac{v_{C}}{R}
\end{aligned}
$$

Equations (12) and (13) can be combined as

$$
\begin{aligned}
& \frac{d i_{L}}{d t}=(1-u) \frac{v_{C}}{L}+\frac{E}{L} u \\
& \frac{d v_{C}}{d t}=-\frac{v_{C}}{R C}-(1-u) \frac{i_{L}}{C}
\end{aligned}
$$

System dynamics can be formulated in the form of $\dot{x}=A x(t)+B u(t)$.

$$
\begin{gathered}
\frac{d i_{L}}{d t}=\frac{v_{C}}{L}+\frac{E-v_{\mathcal{C}}}{L} u \\
\frac{d v_{C}}{d t}=-\frac{i_{L}}{C}-\frac{v_{C}}{R C}+\frac{i_{L}}{C} u
\end{gathered}
$$

Denote $x_{1}=i_{L}$ and $x_{2}=v_{c}$, the $A$ and $B$ matrices become

$$
\begin{gathered}
A=\left[\begin{array}{cc}
0 & \frac{1}{L} \\
-\frac{1}{C} & -\frac{1}{R C}
\end{array}\right] \\
B=\left[\frac{\frac{E-x_{2}}{L}}{\frac{x_{1}}{C}}\right]
\end{gathered}
$$

\section{Sliding Mode Control for Buck-Boost Converter}

The sliding mode control is known as a variable structure control technique, which alters the nonlinear system dynamics by applying a discontinuous control input, and forces the state trajectories to be along the sliding boundaries. The sliding mode method is insensitive to uncertainties due to rapid switching between the continuous structures. The motion of the nonlinear system sliding along these boundaries is called the sliding mode. The geometrical locus consisting of the predetermined boundaries is known as the sliding manifolds $[2,4,7]$.

Consider the nonlinear system dynamics

$$
\dot{x}(t)=g(x(t))+\Phi(x(t)) \cdot u(t)
$$

where $x(t)$ is the state variable, $g($.$) and \Phi($.$) are vector fields in the same space. u(t)$ is the discontinuous control input defined as

$$
u(t)= \begin{cases}U^{+} & \text {for } S(x, t)>0 \\ U^{-} & \text {for } S(x, t)<0\end{cases}
$$


$S(x, t)$ is the predetermined trajectory where state variable $x$ is driven to track the sliding manifold. $U^{+}$and $U^{-}$are either scalar values or function of $x(t)$. Sliding mode properties can be achieved when the reachability, existence, and Lyapunov stability conditions are satisfied.

The reachability condition makes sure that the sliding manifold will be detected and reached, which can be expressed as

$$
S(x) \dot{S}(x)<0
$$

The existence condition ensures the state trajectory will always be forced to move toward the sliding manifold, once the trajectory is located in the vicinity of the sliding manifold. Existence condition can be analytically represented as

$$
\lim _{S \rightarrow 0} S(x) \dot{S}(x)<0
$$

\subsection{Parameter Uncertainties}

Possible uncertainties should be included in the parameters of buck-boost converter model for practical applications. The bounded parameter uncertainties $\Delta_{1}, \Delta_{2}$, and $\Delta_{3}$ are considered, satisfying

$$
\begin{aligned}
& \frac{1}{L}=\frac{1}{\hat{L}}+\Delta_{1} \\
& \frac{1}{C}=\frac{1}{\hat{C}}+\Delta_{2} \\
& \frac{1}{R}=\frac{1}{\hat{R}}+\Delta_{3}
\end{aligned}
$$

where $\frac{1}{\hat{L}^{\prime}}, \frac{1}{\hat{C}^{\prime}}$, and $\frac{1}{\hat{R}}$ are the nominal values.

\subsection{Sliding Manifold for Buck-Boost Converter Control}

The sliding manifold for buck-boost converter is chosen as

$$
S(x)=\left(x_{2}-V^{*}\right)+\rho\left(x_{1}-I^{*}\right)
$$

where $V^{*}$ and $I^{*}$ are the reference values for the output voltage and inductor current, respectively. Desired sliding manifold performance is accomplished by tuning the sliding coefficient $\rho$.

To achieve the reachability condition, Equation (21) must be satisfied:

$$
S(x) \dot{S}(x)<0
$$

which guarantees that the state trajectory will always be driven towards the sliding manifold.

\subsection{Inductor Current Reference Value}

The inductor current is highly dependent on the load and output reference voltage. The desired voltage at the output is achieved when $S(x)=\left(v_{c}-V^{*}\right)=0$, and $\dot{S}(x)$ becomes $\dot{S}(x)=\dot{v}_{\mathcal{c}}=0$. From Equation (16), we have

$$
\frac{d v_{C}}{d t}=0=\frac{-i_{L}}{C}-\frac{V_{C}}{R C}+\frac{i_{L}}{C} u
$$

Solving for $u$ yields

$$
u=1+\frac{v_{\mathcal{C}}}{R i_{L}}
$$


Substituting Equation (28) in Equation (14) results in Equation (29) at the equilibrium point when $\frac{d i_{L}}{d t}=0$ and $v_{c}=V^{*}$.

$$
\frac{d i_{L}}{d t}=\frac{-v_{C}^{2}}{R L i_{L}}+\frac{E}{L}\left(\frac{v_{C}}{R i_{L}}+1\right)
$$

Therefore, the reference inductor current is given by

$$
I^{*}=\frac{V^{*}}{R}\left(\frac{V^{*}}{E}-1\right)
$$

\subsection{First Order Sliding Mode Control Design}

The control $u$ consists of $u_{e q}$ and $u_{s w}$, and can be defined as

$$
u=u_{e q}+u_{s w}
$$

where $u_{e q}$ and $u_{s w}$ are the equivalent control and the switching control, respectively.

By setting $\dot{S}=0, u_{e q}$ can be solved. Based on Equation (26), we have

$$
\dot{S}=-\frac{1}{C} x_{1}-\frac{1}{R C} x_{2}+\frac{x_{1}}{C} u+\rho\left(\frac{1}{L} x_{2}+\frac{E-x_{2}}{L} u\right)
$$

Solving for $u_{e q}$ results in

$$
u_{e q}=\frac{\frac{1}{\hat{C}} x_{1}+\frac{1}{\hat{R} \hat{C}} x_{2}-\rho \frac{1}{\hat{L}} x_{2}}{\rho \frac{1}{\hat{L}}\left(E-x_{2}\right)+\frac{1}{\hat{C}} x_{1}}
$$

Therefore, $\dot{S}$ can be future written as

$$
\dot{S}=-\Delta_{2} x_{1}-\left(\Delta_{3} \frac{1}{\hat{C}}+\frac{1}{\hat{R}} \Delta_{2}+\Delta_{2} \Delta_{1}\right) x_{2}+\Delta_{2} x_{1} u_{s w}+\rho\left(\Delta_{1} x_{2}+\Delta_{1}\left(E-x_{2}\right) u_{s w}\right)
$$

A positive constant $u_{0}$ exists and can be calculated as follows, when bounded uncertainties are taken into account.

$$
u_{0}>\left|\frac{\Delta_{2} x_{1}+\left(\frac{1}{\hat{C}} \Delta_{3}+\frac{1}{\hat{R}} \Delta_{2}+\Delta_{2} \Delta_{3}-\rho \Delta_{1}\right) x_{2}}{\Delta_{1}\left(E-x_{2}\right) \rho+\Delta_{2} x_{1}}\right|
$$

The switching control $u_{s w}$ can be reached as

$$
u_{s w}=-u_{0} \operatorname{sgn}(S(x))
$$

where the signum function $\operatorname{sgn}()$ is defined as

$$
\operatorname{sgn}(S(x))= \begin{cases}1 & S(x)>0 \\ 0 & S(x)=0 \\ -1 & S(x)<0\end{cases}
$$

\subsection{Higher Order Sliding Mode Control Design}

It is well-known that chattering phenomenon (high-frequency oscillation) is the major drawback of the first-order sliding mode control. The oscillatory switching response is observed near the sliding manifold. Chattering causes excessive heat-loss due to stress created on circuit components $[6,15]$. To eliminate the chattering phenomenon inherent in the first-order approach, this manuscript presents a super-twisting-based second-order sliding mode control to improve the buck-boost converter performance. 
It should be noted that the sliding manifold for higher-order sliding mode design is also chosen to be $S(x)=0$. For the $r^{t h}$-order sliding mode method, the following condition is satisfied:

$$
S=\dot{S}=\ddot{S}=\cdots=S^{(r-1)}=0
$$

Therefore, for super-twisting-based second-order sliding mode control, conditions $S(x)=0$ and $\dot{S}(x)=0$ must be satisfied. From Equation (32), we have

$$
\dot{S}=-\frac{1}{C} x_{1}-\frac{1}{R C} x_{2}+\frac{x_{1}}{C} u+\rho\left(\frac{1}{L} x_{2}+\frac{E-x_{2}}{L} u\right)
$$

Taking the second-order derivative of the sliding manifold, we have

$$
\ddot{S}=-\frac{\dot{x}_{1}}{C}-\frac{\dot{x}_{2}}{R C}+\frac{\dot{x}_{1} u}{C}+\frac{x_{1} \dot{u}}{C}+\frac{\rho \dot{x}_{2}}{L}+\frac{\rho}{L}\left(E-x_{2}\right) \dot{u}+\frac{\rho}{L}\left(-\dot{x}_{2}\right) u
$$

Equivalently, we can rewrite $\ddot{S}$ as

$$
\begin{aligned}
\ddot{S} & =-\frac{1}{C}\left(\frac{x_{2}}{L}+\frac{E-x_{2}}{L} u\right)+\left(\frac{\rho}{L}-\frac{1}{R C}\right)\left(-\frac{x_{1}}{C}-\frac{x_{2}}{R C}+\frac{x_{1}}{C} u\right) \\
& +\left[\frac{1}{C}\left(\frac{x_{2}}{L}+\frac{E-x_{2}}{L} u\right)-\frac{\rho}{L}\left(-\frac{x_{1}}{C}-\frac{x_{2}}{R C}+\frac{x_{1}}{C} u\right)\right] u \\
& +\left[\frac{1}{C} x_{1}+\frac{\rho}{L}\left(E-x_{2}\right)\right] \dot{u}
\end{aligned}
$$

Denote the following notations

$$
\begin{aligned}
& \psi=-\frac{1}{C}\left(\frac{x_{2}}{L}+\frac{E-x_{2}}{L} u\right)+\left(\frac{\rho}{L}-\frac{1}{R C}\right)\left(-\frac{x_{1}}{C}-\frac{x_{2}}{R C}+\frac{x_{1}}{C} u\right) \\
& +\left[\frac{1}{C}\left(\frac{x_{2}}{L}+\frac{E-x_{2}}{L} u\right)-\frac{\rho}{L}\left(-\frac{x_{1}}{C}-\frac{x_{2}}{R C}+\frac{x_{1}}{C} u\right)\right] u \\
& \in[-\Psi, \Psi]
\end{aligned}
$$

and

$$
\gamma=\left[\frac{1}{C} x_{1}+\frac{\rho}{L}\left(E-x_{2}\right)\right] \in\left[\Gamma_{m}, \Gamma_{M}\right]
$$

The control signal $u$ for super-twisting-based second-order sliding mode control is $u=u_{e q}+\tilde{u}$, where $u_{e q}$ is already found in the first-order sliding mode derivation, and $\tilde{u}$ can be computed by

$$
\tilde{u}=u_{1}+u_{2}
$$

where

$$
\begin{gathered}
\dot{u}_{1}=-W \operatorname{sgn}(S) \\
u_{2}= \begin{cases}-\lambda\left|S_{0}\right|^{p} \operatorname{sgn}(S) & |S|>\left|S_{0}\right| \\
-\lambda|S|^{p} \operatorname{sgn}(S) & |S| \leq\left|S_{0}\right|\end{cases}
\end{gathered}
$$

The corresponding sufficient conditions for finite-time convergence to the sliding manifold are

$$
\begin{gathered}
W>\frac{\Psi}{\Gamma_{m}} \\
\lambda^{2} \geq \frac{4 \Psi}{\Gamma_{m}^{2}} \frac{\Gamma_{M}(W+\Psi)}{\Gamma_{m}(W-\Psi)} \\
0<p \leq 0.5
\end{gathered}
$$


Furthermore, we select $p=0.5$ to ensure that the optimum real sliding order for 2 -sliding realization is achieved. Then, the switching control component $\tilde{u}$ can be rewritten as $[19,20]$ :

$$
\tilde{u}=-\lambda|S|^{1 / 2} \operatorname{sgn}(S)-W \int \operatorname{sgn}(S) d t
$$

\section{Computer Simulation Studies}

In computer simulation studies, the solar panels have nearly $100 \mathrm{~kW}$ electrical power generation capacity. The overall design diagram is illustrated in Figure 10. As shown in Table 1, $100 \mathrm{~kW}$ generation capacity is achieved with 374 panels (17 solar panels in series and 22 panels in parallel). This combination applies $\left(17 \times 30.9 \mathrm{~V}=525.3 V_{m p p}\right)$ to $P \& O$ MPPT-controlled boost converter. The exact maximum installed solar power capacity of the array can be calculated by the multiplication of $V_{m p p}, I_{m p p}$ and the number of solar panels. Hence, the total install capacity is $101.8 \mathrm{~kW}$ electrical power. Solar irradiation is considered to be changing in the range between $600 \mathrm{~W} / \mathrm{m}^{2}$ and $1000 \mathrm{~W} / \mathrm{m}^{2}$, as shown in Figure 11.

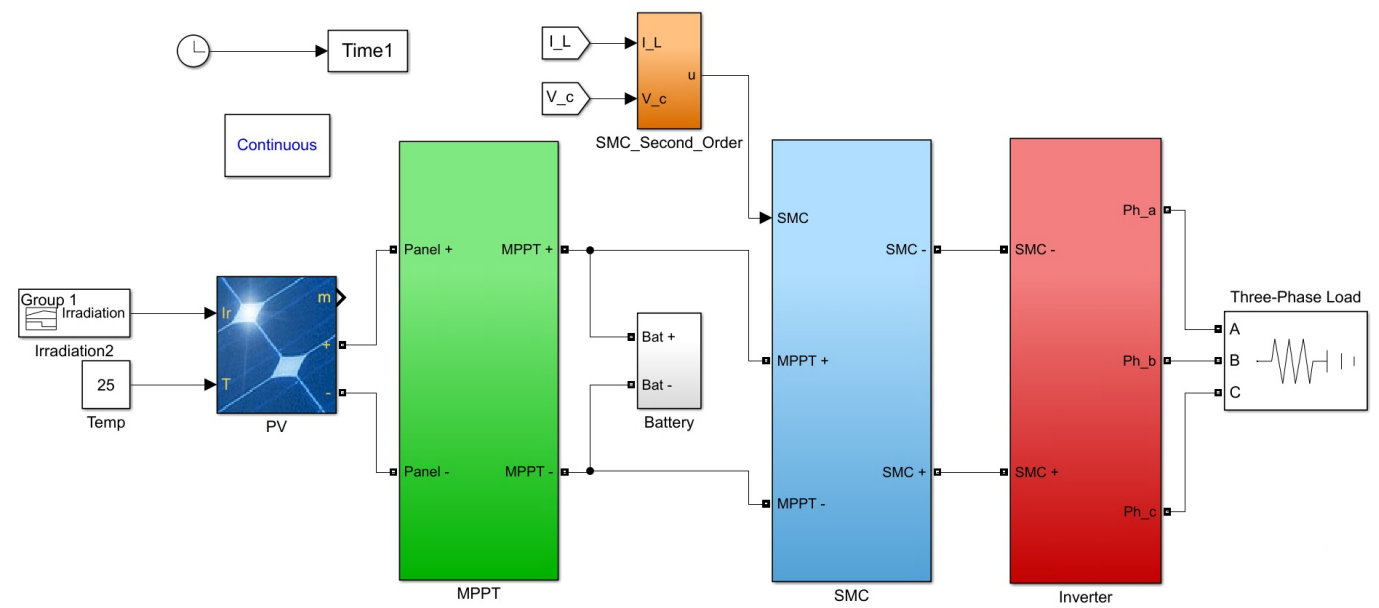

Figure 10. Overall Design.

The output of photovoltaic panels is connected to a MPPC-controlled boost converter to charge standard $650 \mathrm{~V}$ battery, which maximizes the power generation capacity from the solar panels. In order to match the common DC link voltage of $1000 \mathrm{~V}$, we propose a firstorder and a second-order sliding mode controlled (SMC) buck-boost converter to step up voltage from $650 \mathrm{~V}$ battery voltage to $1000 \mathrm{~V}$ common DC link voltage. The DC-DC power converter parameters are summarized in Table 2. The SMC controlled buck-boost converter provides us with the flexibility to match any common DC link voltage, by stepping up or reducing the battery voltage. Furthermore, the voltage-oriented control(VOC) space-vector pulse-width-modulated inverter can supply the three-phase output voltages to directly supply the micro-grid or AC load. For computer simulation studies, a three-phase load was directly supplied by the inverter.

Table 2. DC-DC power converter parameters.

\begin{tabular}{ccc}
\hline- & MPPT Based Boost Converter & SMC Based Buck-Boost Converter \\
\hline Inductance & $33 \mathrm{mH}$ & $400 \mathrm{mH}$ \\
Capacitance & $10 \mathrm{mF}$ & $1 \mathrm{mF}$ \\
Input voltage & $525.3 \mathrm{~V}$ & $651 \mathrm{~V}$ \\
Output voltage & $651 \mathrm{~V}$ & $1000 \mathrm{~V}$ \\
\hline
\end{tabular}

Computer simulation results are summarized in the following figures. Figure 11 shows the time-varying solar irradiation in the range between $600 \mathrm{~W} / \mathrm{m}^{2}$ and $1000 \mathrm{~W} / \mathrm{m}^{2}$ 
over $10 \mathrm{~h}$ daylight duration. Figure 12 illustrates the photovoltaic array output voltage over the changing solar irradiation in Figure 11. Note that the generated voltage from solar panel is about $525 \mathrm{~V}$.

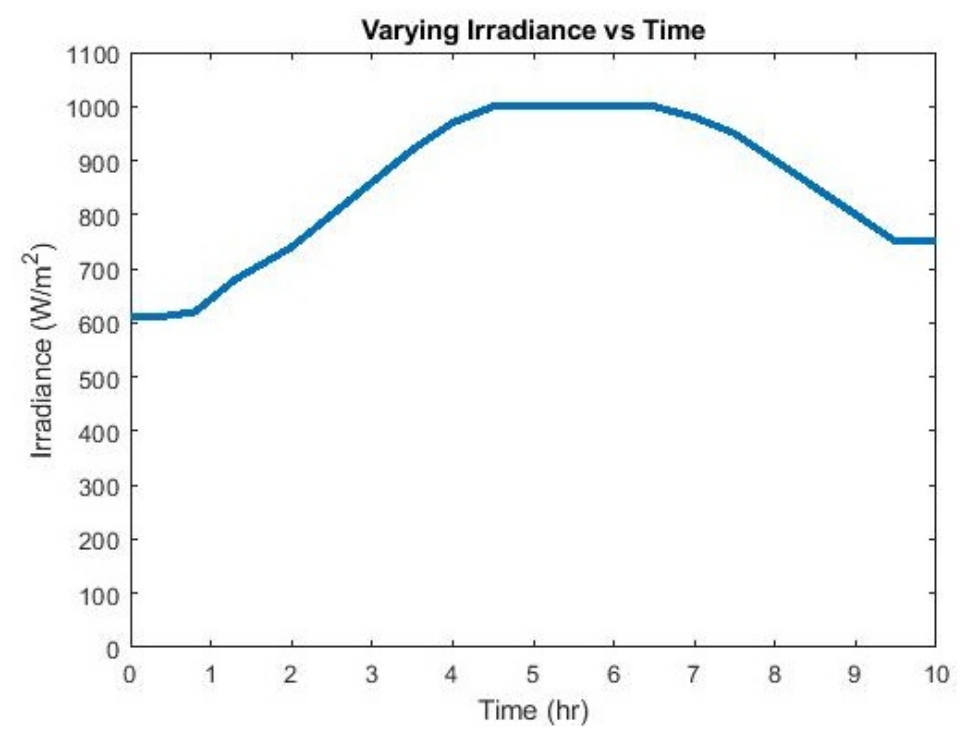

Figure 11. Varying solar irradiation.

Figures 12-14 show that maximum power point of the solar array is accurately tracked by the MPPT controller at $1000 \mathrm{~W} / \mathrm{m}^{2}$ irradiation. Figures $15-17$ show the $P \& O$ based MPPT response under changing irradiation from $600 \mathrm{~W} / \mathrm{m}^{2}$ to $1000 \mathrm{~W} / \mathrm{m}^{2}$. Hence, the $P \& O$-based maximum powerpoint tracking control successfully ensures high accuracy near the maximum powerpoint ratings (525.3 V of $V_{m p p}, 193.8 \mathrm{~A}$ of $I_{m p p}$, and $101.8 \mathrm{~kW}$ of $\left.P_{m p p}\right)$.

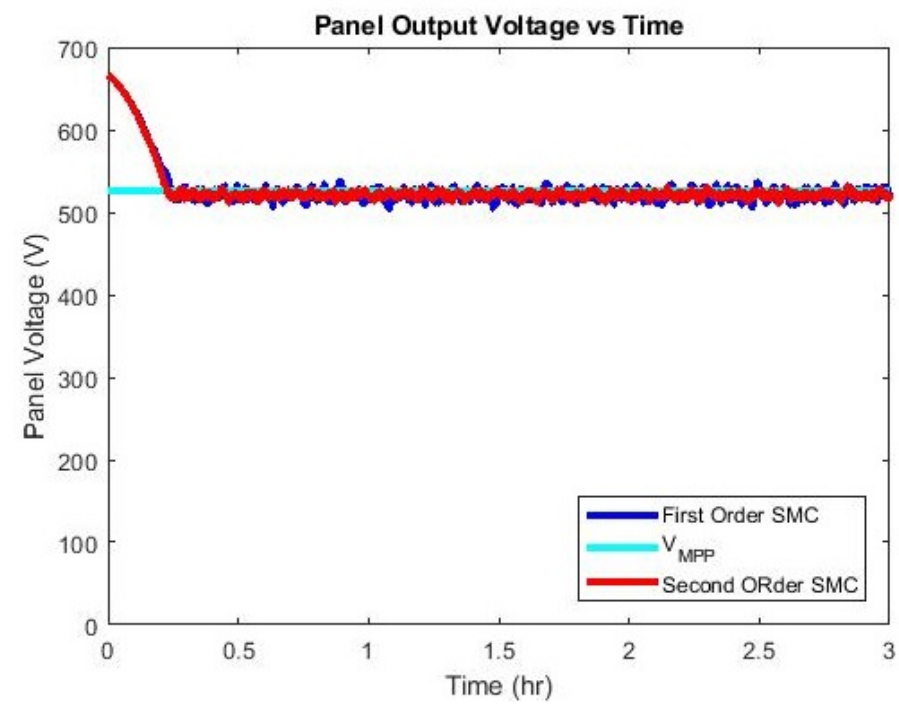

Figure 12. PV array output voltage at $1000 \mathrm{~W} / \mathrm{m}^{2}$. 


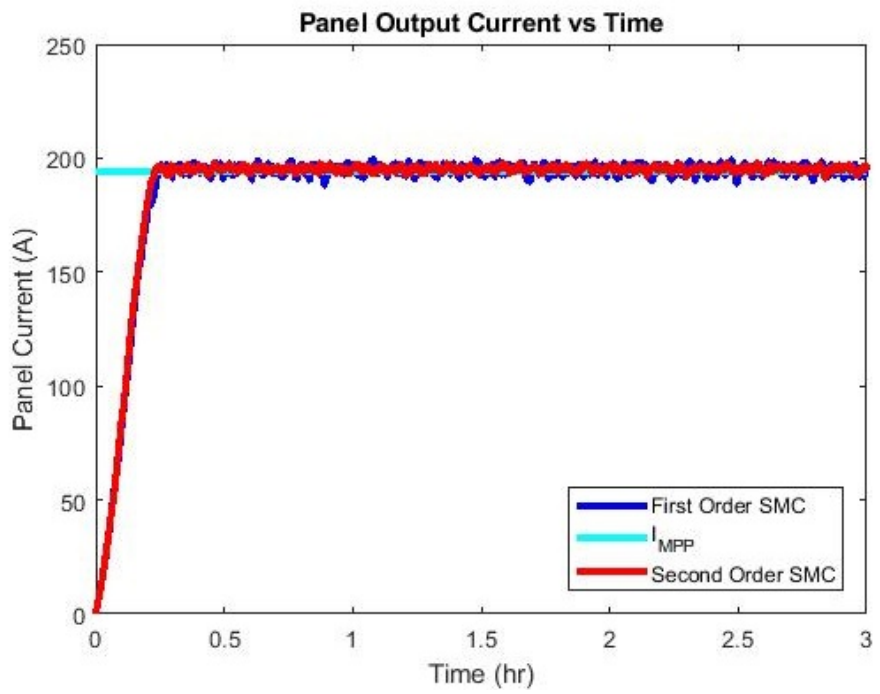

Figure 13. PV array output current at $1000 \mathrm{~W} / \mathrm{m}^{2}$.

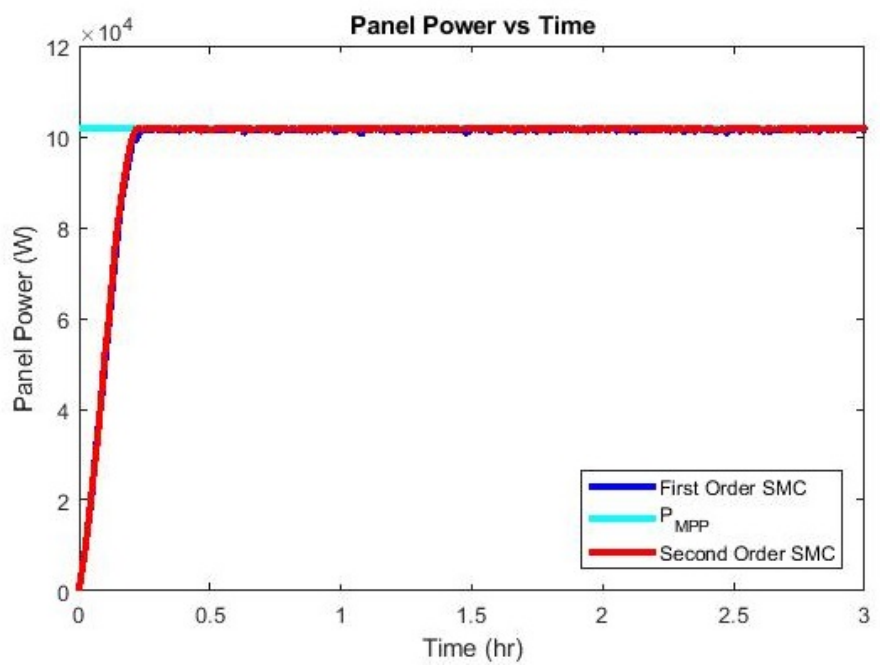

Figure 14. PV array output power at $1000 \mathrm{~W} / \mathrm{m}^{2}$.

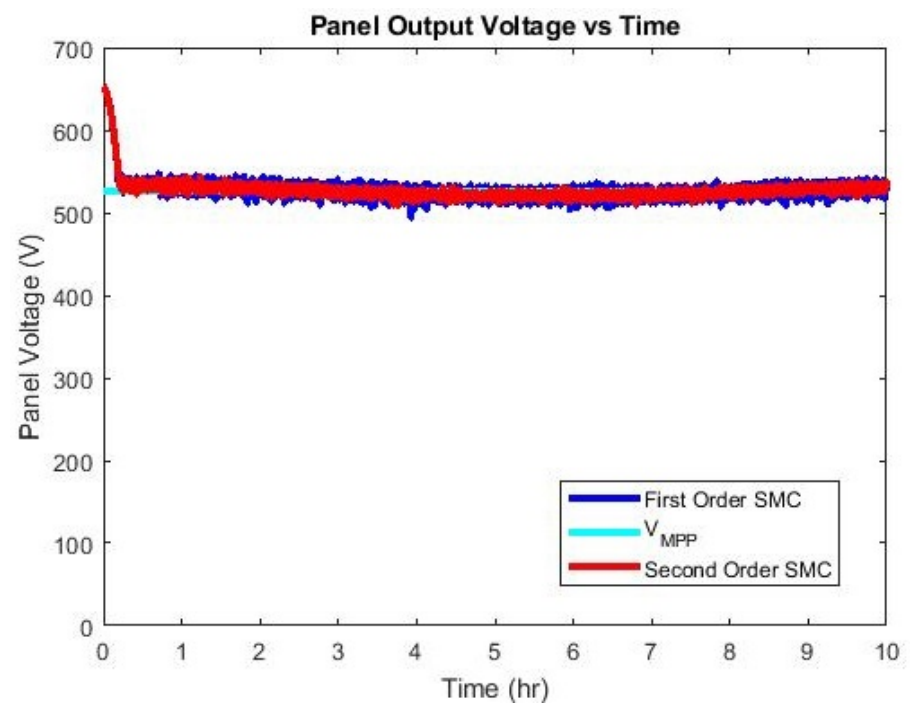

Figure 15. PV array output voltage over the changing irradiation. 


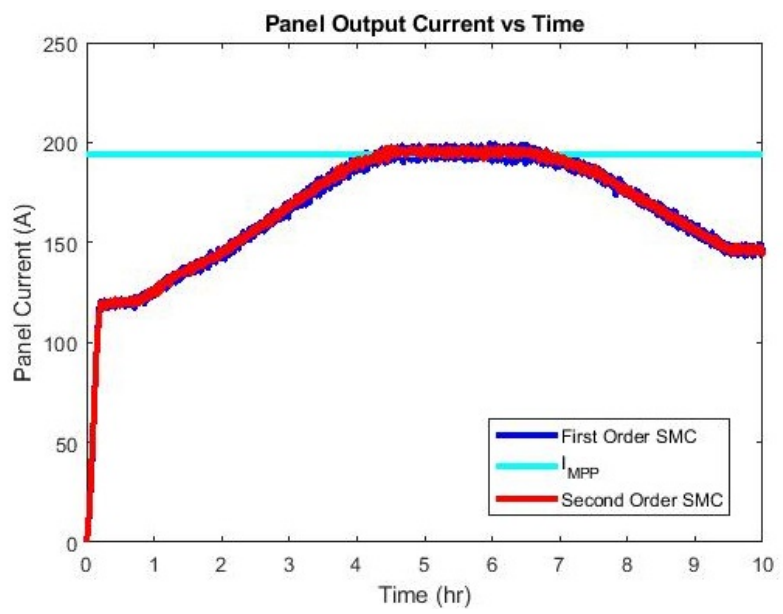

Figure 16. PV array output current under changing irradiation.

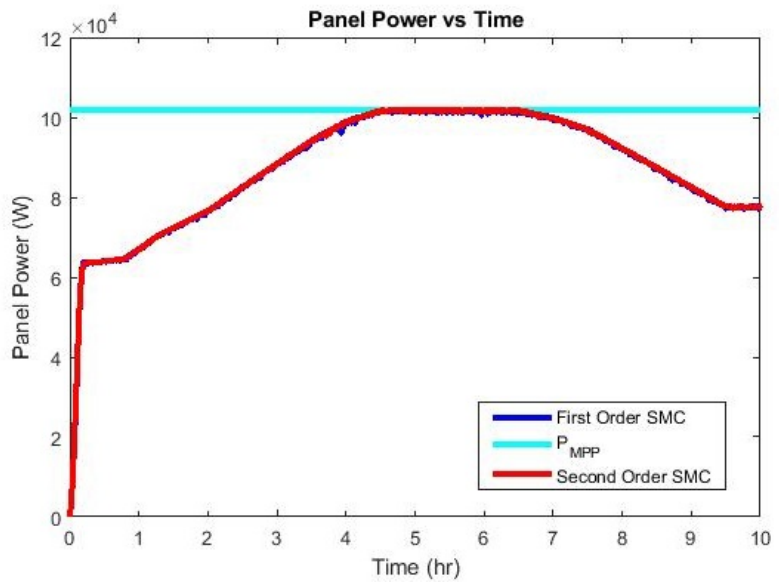

Figure 17. PV array output power under changing irradiation.

Figures 18-21 show the I-V and P-V responses of the solar array under changing and constant solar irradiation conditions. From these results, $666.4 \mathrm{~V}$ is observed before reaching the maximum power-point ratings, since solar panels are initially open-circuited. It can also be seen that second-order sliding mode control design significantly reduces the chattering effect under changing solar irradiation. Once the maximum operation point is reached, the MPPT controller maintains the constant duty cycle, unless a variation is observed.

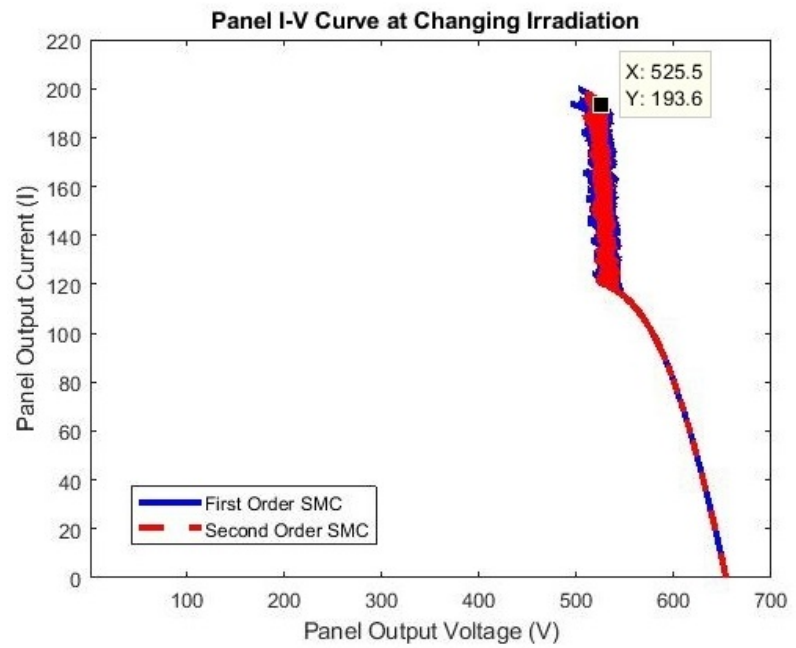

Figure 18. PV array I-V characteristic under changing irradiation. 


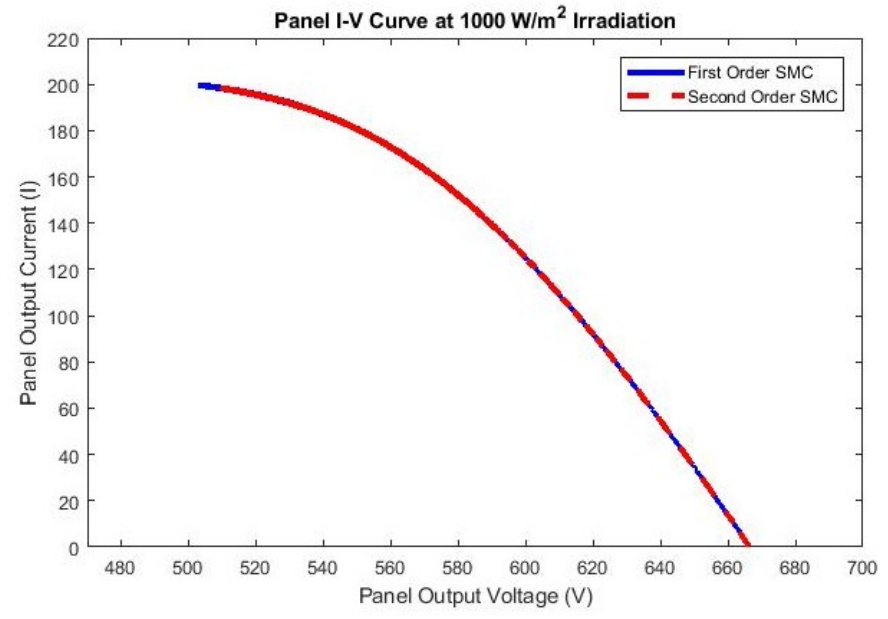

Figure 19. PV array $\mathrm{I}-\mathrm{V}$ characteristic at $1000 \mathrm{~W} / \mathrm{m}^{2}$.

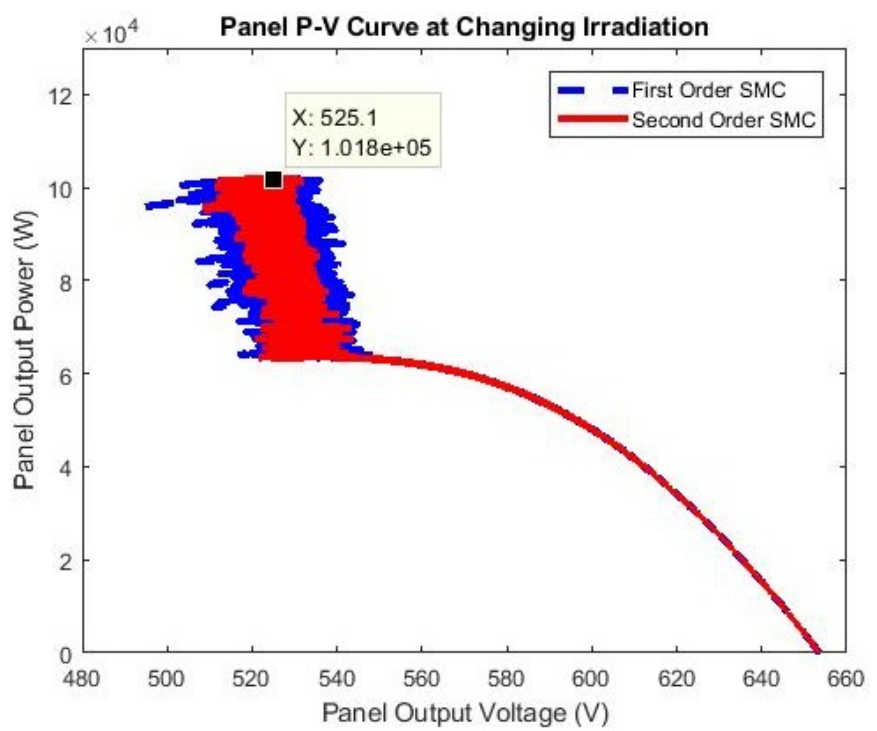

Figure 20. PV array P-V characteristic under changing irradiation.

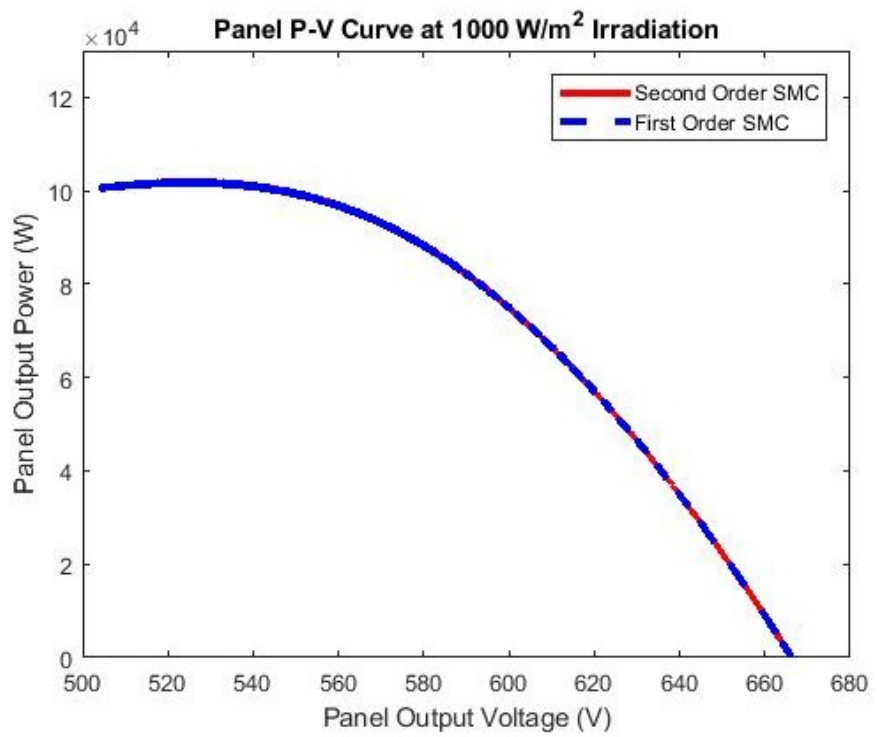

Figure 21. PV array P-V characteristic at $1000 \mathrm{~W} / \mathrm{m}^{2}$. 
Figures 22 and 23 show the output waveform of buck-boost converter, which indicate that the second-order sliding mode control significantly reduces chattering phenomenon, compared with the first-order approach. This improvement leads to a quasi-stable DC voltage for the common DC link at $1000 \mathrm{~V}$.

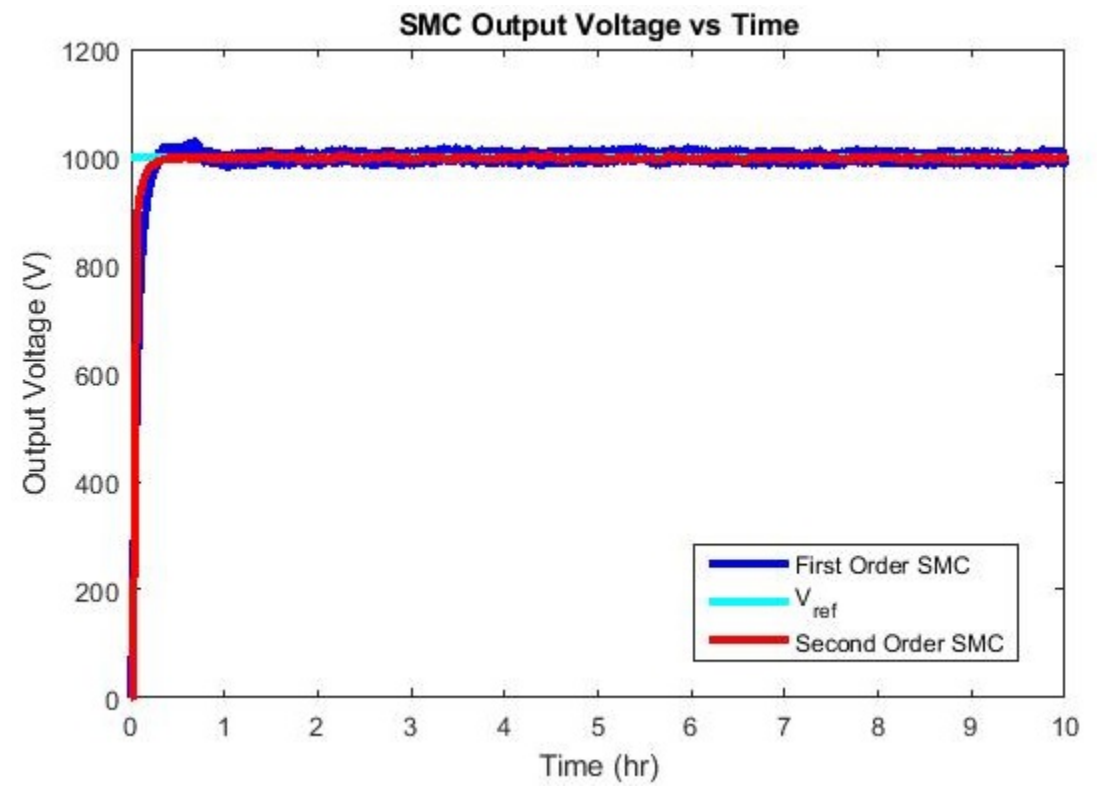

Figure 22. SMC buck-boost converter output voltage under changing irradiation.

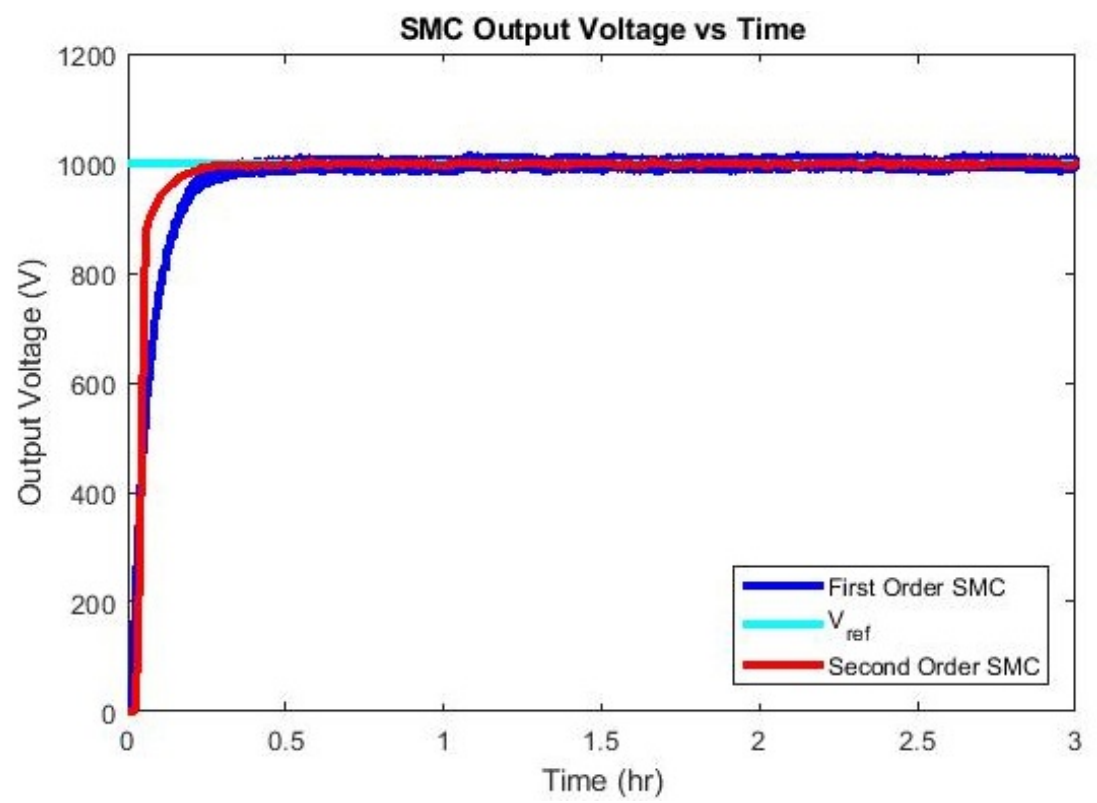

Figure 23. SMC buck-boost converter output voltage at $1000 \mathrm{~W} / \mathrm{m}^{2}$.

Figure 24 shows control signals $u$ for both first-order and second-order sliding-modecontrol-based buck-boost converter, which serves as the gate signals for the IGBT inverter. 


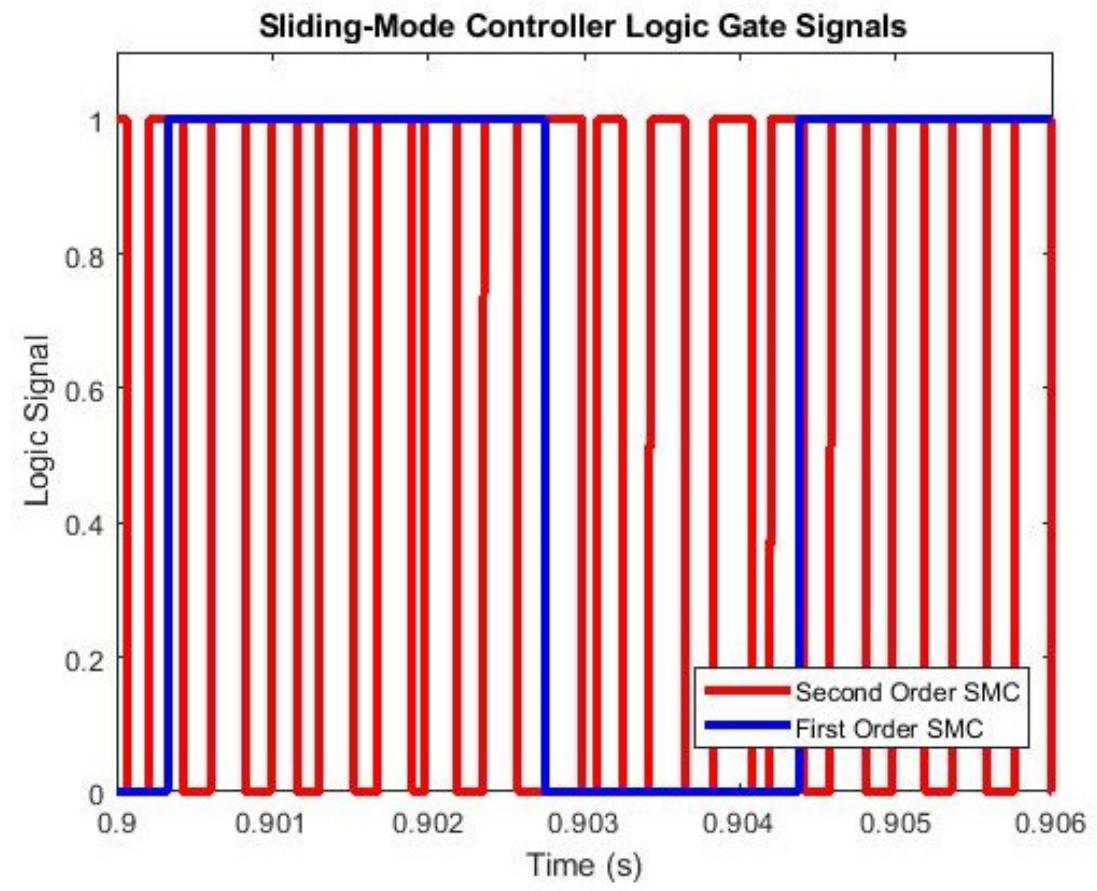

Figure 24. SMC buck-boost converter gate control signal.

Figures 25 and 26 show the line-to-line and line-to-neutral output voltage profile of voltage-oriented control (VOC) based space-vector pulse-width-modulated inverter, feeding three-phase power to the micro-grid or industrial AC loads.
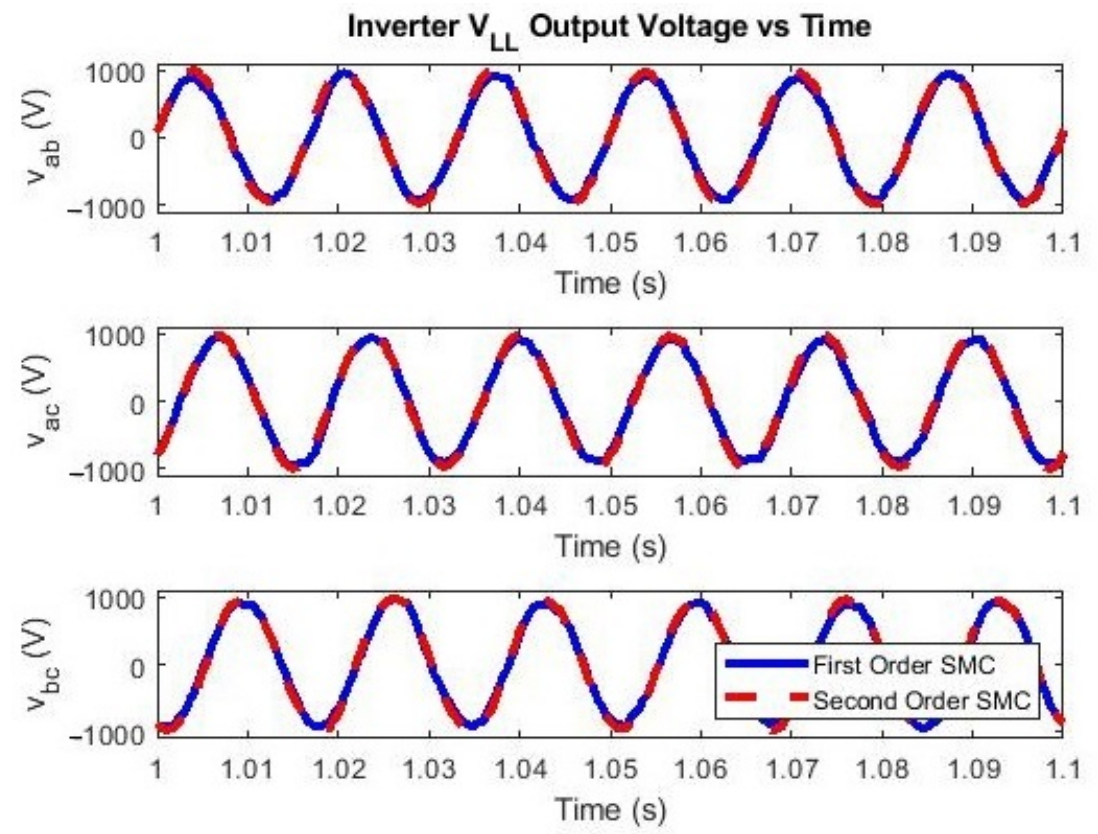

Figure 25. SVPWM inverter $V_{L L}$ output voltage under changing irradiation. 

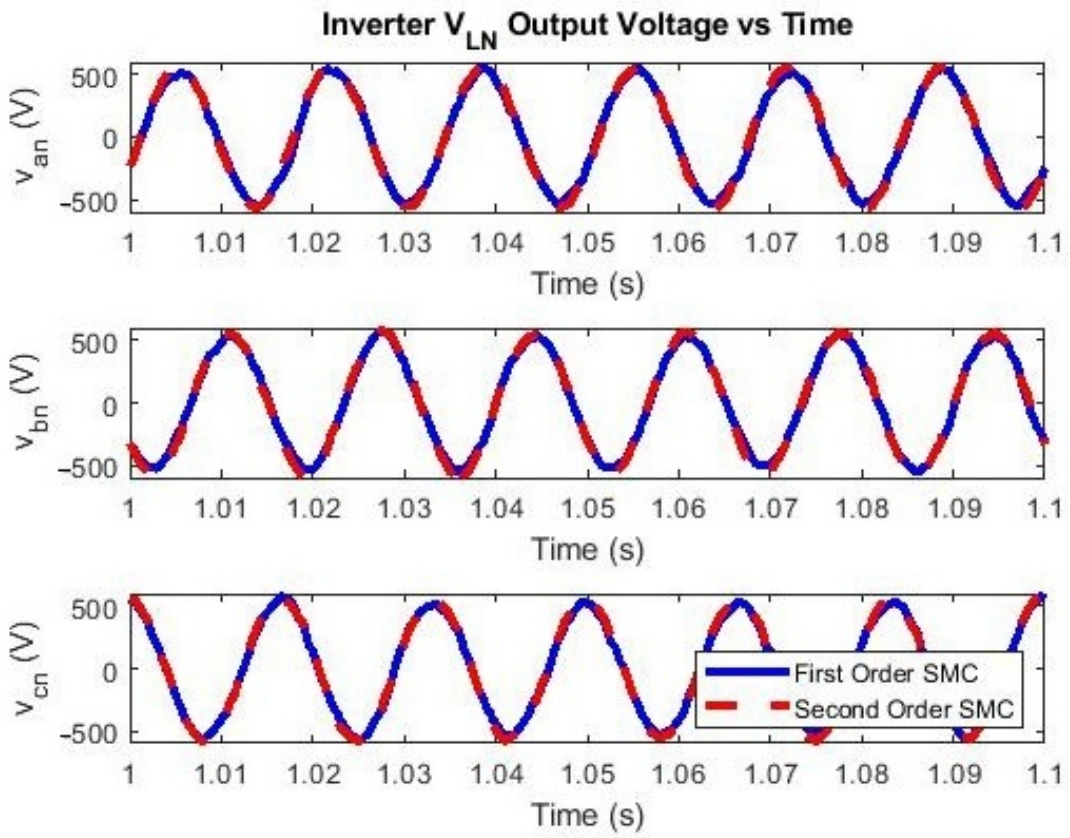

Figure 26. SVPWM inverter $V_{L N}$ output voltage under changing irradiation.

\section{7. dSPACE Hardware-in-the-Loop Implementations}

To demonstrate the effectiveness and robustness of the proposed approach, we also implemented the proposed super-twisting-based second-order sliding-mode-control-based solar energy conversion system using dSPACE hardware-in-the-loop platform. The real-time measurement data are captured and displayed using dSPACE ControlDesk in Figure 27. As shown, the dSPACE HIL measured line to line voltage closely matches the simulation result in Figure 25.

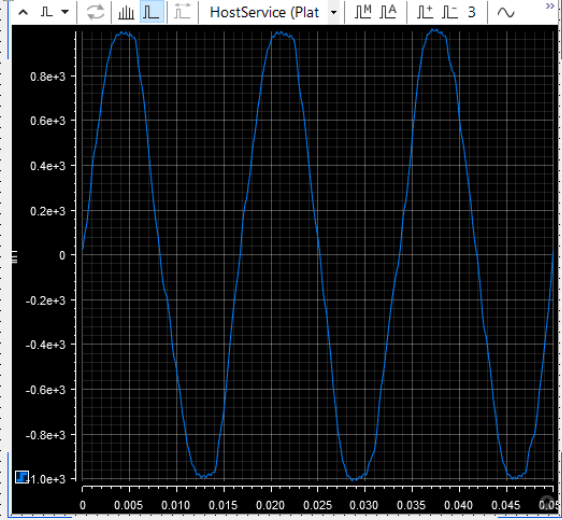

$\mathrm{Vab}$

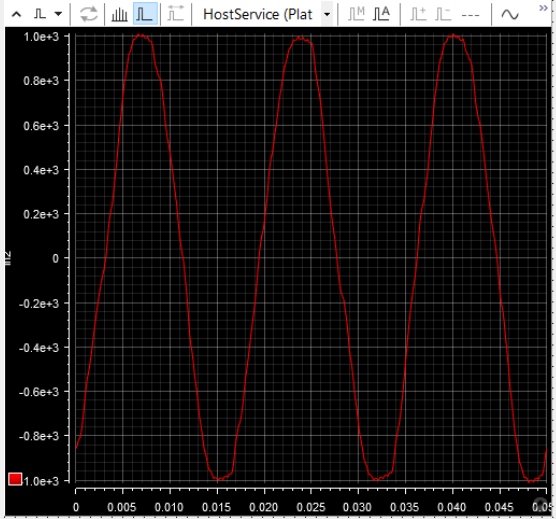

$\mathrm{Vbc}$

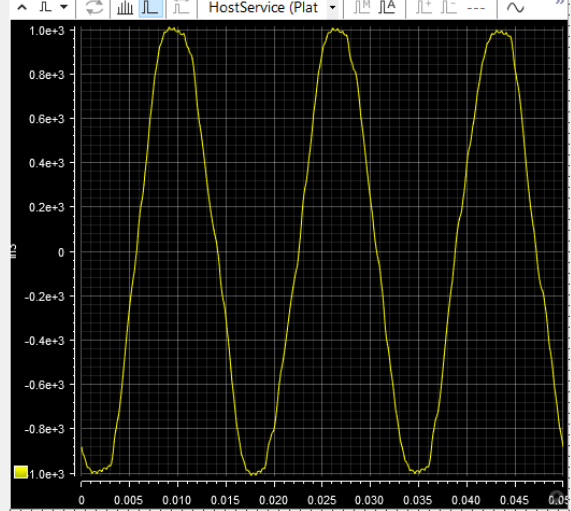

$\mathrm{Vca}$

Figure 27. dSPACE measured line-to-line voltage.

\section{Conclusions}

Novel first- and second-order sliding mode controls (SMC) have been proposed for solar energy conversion systems. The optimal power-point of solar panels can be precisely tracked using the perturbation and observation (P\&O)-based maximum powerpoint tracking (MPPT) method, which maximizes the power generation efficiency of the solar panels under irradiance fluctuations. The SMC-based buck-boost converter can step-up and step-down the battery voltage to match the common DC link voltage. The common DC link is further feeding to the voltage-oriented control (VOC)-based space- 
vector pulse-width-modulated inverter to supply three-phase power for the micro-grid or industrial AC loads. Both computer simulation results and dSPACE hardware-in-theloop hardware implementation have shown that second-order sliding-mode-control-based DC-DC power converter significantly reduced the chattering phenomenon, enhanced the overall power conversion efficiency and perfectly tracked the maximum power-point. The proposed sliding-mode-control-based solar energy conversion system scheme can serves as a powerful alternative to the existing solar energy conversion techniques.

Author Contributions: Conceptualization, X.W. and M.G.; methodology, X.W. and A.G.L.; software, M.G. (simulation) and G.Z. (HIL); writing-original draft preparation, M.G., G.Z. and X.W.; writing-review and editing, G.Z. and X.W.; supervision, X.W.; project administration, A.G.L. All authors have read and agreed to the published version of the manuscript.

Funding: This research received no external funding.

Institutional Review Board Statement: Not applicable.

Informed Consent Statement: Not applicable.

Acknowledgments: Guangping Zhuo's research is supported by Shanxi Science and Technology Foundation, Project " Research on the Core Scalable Guaranteed Intelligent Service Model for CrossNetwork Virtual Reality", Project number: 201801D121147.

Conflicts of Interest: The authors declare no conflict of interest.

\section{References}

1. Dunlop, J.P. Photovoltaic Systems, 2nd ed.; American Technical Publishers: Orlando Park, IL, USA, 2010.

2. Sira-Ramirez, H.; Rios-Bolivar, M. Sliding mode control of DC-to-DC power converters via extended linearization. IEEE Trans. Circuits Syst. Fundam. Theory Appl. 1994, 41, 652-661. [CrossRef]

3. Tan, S.-C.; Lai, Y.M.; Tse, C.K. A unified approach to the design of PWM-based sliding-mode voltage controllers for basic DC-DC converters in continuous conduction mode. IEEE Trans. Circuits Syst. Regul. Pap. 2006, 53, 1816-1827.

4. Reitz, M.A.; Wang, X. Robust sliding mode control of buck-boost DC-DC converters. In Proceedings of the ASME 2016 Conference on Dynamic Systems and Control (DSCC 2016-9804), Minneapolis, MN, USA, 12-14 October 2016; pp. 1-10.

5. Oucheriah, S.; Guo, L. PWM-based adaptive sliding-mode control for boost DC-DC converters. IEEE Trans. Ind. Electron. 2013, 60, 3291-3294. [CrossRef]

6. Perruquetti, W.; Barbot, J.P. (Eds.) Sliding Mode Control in Engineering; Marcel Dekker: New York, NY, USA, 2002.

7. Liu, J. Sliding Mode Control Using MATLAB; Academic Press: Cambridge, MA, USA, 2017.

8. Ling, R.; Maksimovic, D.; Leyva, R. Second-Order Sliding-Mode Controlled Synchronous Buck DC-DC Converter. IEEE Trans. Power Electron. 2016, 31, 2539-2549. [CrossRef]

9. Wu, B.; Lang, Y.; Zargari, N.; Kouro, S. Power Converters in Wind Energy Conversion Systems; Wiley-IEEE Press: Hoboken, NJ, USA, 2011; pp. 87-152.

10. Khanna, R.; Zhang, Q.; Stanchina, W.E.; Reed, G.F.; Mao, Z. Maximum Power Point Tracking Using Model Reference Adaptive Control. IEEE Trans. Power Electron. 2014, 29, 1490-1499. [CrossRef]

11. Sunmodule Plus SW 270 Mono Black, User Manual, SolarWorld. Available online: www.solarworld.com (accessed on 10 August 2021).

12. de Brito, M.A.G.; Galotto, L.; Sampaio, L.P.; Melo, G.D.A.E.; Canesin, C.A. Evaluation of the Main MPPT Techniques for Photovoltaic Applications. IEEE Trans. Ind. Electron. 2013, 60, 1156-1167. [CrossRef]

13. Babu, B.C.; Gurjar, S. A Novel Simplified Two-Diode Model of Photovoltaic (PV) Module. IEEE J. Photovolt. 2014, 4, 1156-1161. [CrossRef]

14. Femia, N.; Petrone, G.; Spagnuolo, G.; Vitelli, M. Power Electronics and Control Techniques for Maximum Energy Harvesting in Photovoltaic Systems; CRC Press: Boca Raton, FL, USA, 2013.

15. Reitz, M.A. Nonlinear Robust Control of Permanent Magnet Synchronous Motors with Applications to Hybrid Electric Vehicles. Master's Thesis, Southern Illinois University, Edwardsville, IL, USA, May 2016.

16. Gursoy, M. Sliding Mode Power Electronics Control for Stand-Alone Photo-Voltaic Energy Systems. Master's Thesis, Southern Illinois University, Edwardsville, IL, USA, May 2019.

17. Ryvkin, S.; Lever, E.P. Sliding Mode Control for Synchronous Electric Drives; CRC Press: Boca Raton, FL, USA, 2011.

18. Gursoy, M.; Lozowski, A.; Wang, X. Power Converter Sliding Mode Control Design for Photovoltaic Energy Conversion Systems. In Proceedings of the ASME 2019 International Mechanical Engineering Congress and Exposition, Salt Lake City, UT, USA, 8-14 November 2019; Paper No. IMECE2019-10110.

19. Wang, X.; Reitz, M.; Yaz, E.E. Field Oriented Sliding Mode Control of Surface-Mounted Permanent Magnet AC Motors: Theory and Applications to Electrified Vehicles. IEEE Trans. Veh. Technol. 2018, 67, 10343-10356. [CrossRef] 
20. Zhuo, G.; Hostettler, J.; Gu, P.; Wang, X. Robust Sliding Mode Control of Permanent Magnet Synchronous Generator-Based Wind Energy Conversion Systems. Sustainability 2016, 8, 1265. [CrossRef]

21. Abdelsalam, A.K.; Massoud, A.M.; Ahmed, S.; Enjeti, P.N. High-performance adaptive perturb and observe MPPT technique for photovoltaic-based microgrids. IEEE Trans. Power Electron. 2011, 26, 1010-1021. [CrossRef]

22. Elgendy, M.A.; Zahawi, B.; Atkinson, D.J. Assessment of perturb and observe MPPT algorithm implementation techniques for PV pumping applications. IEEE Trans. Sustain. Energy 2012, 3, 21-33. [CrossRef]

23. Petrone, G.; Spagnuolo, G.; Vitelli, M. A multi-variable perturb-and observe maximum power point tracking technique applied to a single stage photovoltaic inverter. IEEE Trans. Ind. Electron. 2011, 58, 76-84. [CrossRef]

24. Nousiainen, L.; Puukko, J.; Maki, A.; Messo, T.; Huusari, J.; Jokipii, J.; Viinamaki, J.; Lobera, D.T.; Valkealahti, S.; Suntio, T. Photovoltaic generator as an input source for power electronic converters. IEEE Trans. Power Electron. 2013, 28, 3028-3038. [CrossRef]

25. Atik, L.; Petit, P.; Sawicki, J.P.; Ternifi, Z.T.; Bachir, G.; Della, M.; Aillerie, M. Maximum power point tracking algorithm based on sliding mode and fuzzy logic for photovoltaic sources under variable environmental conditions. AIP Conf. Proc. 2017, $1814,020063$. 